\title{
Developing an explanatory model for the process of online radicalisation and terrorism
}

Robyn Torok

\begin{abstract}
While the use of the internet and social media as a tool for extremists and terrorists has been well documented, understanding the mechanisms at work has been much more elusive. This paper begins with a grounded theory approach guided by a new theoretical approach to power that utilizes both terrorism cases and extremist social media groups to develop an explanatory model of radicalization. Preliminary hypotheses are developed, explored and refined in order to develop a comprehensive model which is then presented. This model utilizes and applies concepts from social theorist Michel Foucault, including the use of discourse and networked power relations in order to normalize and modify thoughts and behaviors. The internet is conceptualized as a type of institution in which this framework of power operates and seeks to recruit and radicalize. Overall, findings suggest that the explanatory model presented is a well suited, yet still incomplete in explaining the process of online radicalization.
\end{abstract}

Keywords: Foucault, Psychiatric power, Online radicalization, Power relations, Normalization, Terrorism

\section{Introduction}

The use of the internet for terrorist recruitment and operations has increased significantly in recent years. Part of that expansion is an embracing of Western social media including Facebook, Twitter and YouTube. While this phenomenon is well documented, what is more difficult to determine due to limited research, are the mechanisms and power relations that underlie this phenomenon of online media used to promote radicalization which in some cases can develop into terrorism. Currently, more traditional models are utilized that look at concepts such as psychological warfare, propaganda, indoctrination and data mining [1]. Furthermore, narratives are viewed as an important aspect of seduction for radicalization [1,2].

This paper examines these mechanisms and power relations using the analytical framework from historian and philosopher Michel Foucault; in particular, his earlier work on psychiatric power [3]. Foucault's approach on psychiatric power focused on the asylum as an institution in order to modify and normalize extreme behaviors of those who were deemed as 'mad'. What is particularly significant from Foucault's work is that terms such as 'madness' and psychiatric discourses are historically constituted through power relations [4].

Correspondence: rtorok@our.ecu.edu.au

Security Research Institute, Edith Cowan University, Perth, Australia
Naturally the term 'jihad', should also be subject to historical contextualization. However, it is not the intention of this paper to reproduce what others have done, such as a genealogy of Islamic ideas [5]. Rather, this paper looks at how the institutional context for these discourses has shifted, particularly in light of the "war on terror'. Traditional 'institutions' such as training camps are becoming increasingly difficult to operate given the fact that they are continually targeted. In response, terrorists have had to create new forms of institutions to recruit, radicalize and train. Most significant is the use of the online institution.

This shift to an online institution reflects one of the most important strategic shifts and considers Foucault's methodology which relies on examining historical and strategic shifts in practices as part of his methodological approach [6,7]. Furthermore, these strategic shifts reflect a transformation in power dynamics where the weaker party in asymmetrical warfare can further disperse relationships through a giant open network. Coupled with these shifts, it is also useful to include Foucault's discourse of a 'game' when conceptualizing how either discourses or practices change over time, and very much parallels the online cyber environment that has its own set of 'rules' [7]. Consequently it is expected that a shift 
in practices will also involve a shift in the nature and type of threat posed by terrorist groups.

The recent case of Arid Uka reveals a disturbing new trend in online terrorism, that of the loner, with no clear organizational affiliations or connections [8]. It marks a shift away from training camps and small group affiliations towards the online institution [9]. In other words, 'The terrorists we should fear most are self-recruited wannabes who find purpose in terror and comrades on the Web.' [9, p. 37]. So the key question is, what drives this new breed of recruit? It is not poverty, not even necessarily religion, but a sense of marginalization and a search for significance [9]. What is most concerning is that the internet has become an online institution for gathering and coordinating these marginalized individuals.

In recent years there has been an increasing reliance on internet technologies primarily because they allow good targeting of marginalized individuals, anonymity and decentralization [10]. Originally the focus has been on terrorist created web sites, now the focus has shifted and spread to Western social media sites and forums such as Facebook, Twitter, YouTube and Yahoo groups [10]. These forums offer distinct advantages in that they enable terrorists to attract or lure individuals to a cause as well as creating a mechanism to coordinate attacks [10]. These media forums have become the new institutions of radicalization and terrorism. It is within these institutions where attitudes are shaped, rationalities are developed and individuals reshaped for the path of jihad.

\section{Methodology}

This paper used qualitative data collection and analysis. Specifically, it followed a grounded theory model of cyclic development in terms of hypothesis generation, testing and refinement [11]. The final explanatory model can be considered the result of hypothesis generation resulting from a guiding theoretical framework in conjunction with a literature analysis on current research, social media research and post fact terrorist cases.

Grim and others utilize the idea of qualitative hypothesis testing in focus group interviews in order to test a generated hypothesis [12]. In like fashion, this study utilized several terrorist case profiles coupled with ten extremist groups using their social media group pages on Facebook over a period of three months in order to confirm, refine or modify the analytical framework developed. The internet is regarded by researchers as a cultural domain in its own right [13], and this is harmonious with the exploratory notion of the internet as an institution. Due to ethical boundaries, analysis was restricted to public domain group pages and did not focus on personal profile pages. Continual data generation, hypothesis refinement and checking were conducted in order to achieve data saturation [12].

This study combined both pre terrorism data through social media analysis of radicalized groups coupled with post fact data of well-known terrorism cases. Together, these formed a more comprehensive profile of extremist and terrorist sociology that was used to develop concepts in comparison with Foucault's analytic of psychiatric power. Points of agreement and disagreement were both actively sought in order to refine the hypothesis generated.

\section{Results of grounded theory analysis}

In developing a substantive model for radicalization and terrorism, data generation was subdivided into several areas using Foucault's analytic framework of psychiatric power. From this, a preliminary hypothesis was proposed, which was then further developed.

\section{The online environment as an isolating influence}

An obvious starting point for exploring the nature of the online environment is its role in terrorist cases. Consider Faisal Shahzad, the accused Time Square bomber. His profile classifies him as a loner, only going out at night and focusing on activities on his computer (also has university background in computing) [14]. Likewise, Nidal Hasan, the Fort Hood killer was also classified a very quiet and was also found to have spent extensive time on the internet [15]. Numerous other cases also support extensive online engagement [9]. From these case studies the following hypothesis was generated:

- H1:The online environment becomes a self-imposed institution, whereby individuals become isolated in terms of developing rationalities.

Although, individuals in these terrorism cases were not completely separated from the rest of the world, they did exhibit a withdrawal from interaction with others. The word institution was chosen because it specifically captures the nature of this isolation. An institution has walls and boundaries that separate it from the rest of the world. Typical institutions that can powerfully reshape individuals include prisons, schools and mental institutions. In contrast to traditional institutions, the online institution is one chosen by the individual rather than one that a person is forced into.

In a search for disconfirming data, it was found that the nature of institutions did vary and were not always online. For example there were cases of small splinter groups that first met in mosques such as the Detroit Sleeper Cell [16] and the Benbrika Case [17]. Additionally, prisons have also become another institution for recruiting and radicalizing [16]. In addition, institutions 
have been combined to include both small groups coupled with online material such as the Madrid Train Bombers [9]. Nonetheless, the online environment has proven to be a salient institution for terrorism. Therefore, the next point of investigation lies with describing the nature of this institution.

Commentators have noted a move toward more open online access to extremist material [18]. An analysis of Facebook revealed that groups were set up with varying levels of openness: open access, requested access and hidden. As a general trend, more extreme groups tend to be less open, thus layering access to the level of extremism on social media. However, there are disconfirming cases where extreme material has open access, but is also reproduced; it seems with the expectation of having this material deleted (See following subsection). Additionally, members of extremist groups are cautioned about being infiltrated by intelligence agents with warnings posted.

Sample posts highlighting security concerns. Here a number of sample posts illustrate the concern over viewing by intelligence agencies.

- $\quad$ Do not accept or invite any more than 10 friends a day] [VR05]

- [Just so everyone knows, some of you are coming up as being online twice. Be careful I think they are hacking our accounts. In particular, call to jihad members] [SFA09]

- [Someone has hacked our group] [SFA08]

- [Allah protect out accounts] [PA08]

- [... then I'll get disabled again in 2 or 3 weeks al hamdulillah ala kulli kaal] [SFA08]

Source: Group pages including Voice of Islamic Resistance 4

The number 4 after the name indicates that the page has been previously shut down three times. What is also very evident is the large number of Islamic extremist groups and pages present on Facebook and these keep reappearing even after being shut down.

Another issue in exploring the online institution is the way that individuals interact with it. In exploring the link between internet use and depression with terrorism, it is difficult to make generalized comments. However, cases do exist that link emotional issues, online use and terrorism. The most notable being Nidal Hasan whose profile reveals that he was disturbed through his dealing with veterans [15]. Similarly, Mohamed Mohamud (Portland bomb plot) harbored high levels of anger and resentment towards his family [19]. While, there has not been any formal diagnosis of depression, these cases clearly show that the perpetrators were disaffected and harbored emotional issues.
The online environment used to influence thoughts and behaviours

Perhaps one of the most important aspects of this investigation is the way that the online institution is used to influence ways of thinking and ways of viewing the world. Given the fact that many terrorist cases are correlated with high exposure to the internet $[9,14,15,20]$, the following hypothesis was proposed:

- H2:The online environment is a critical mechanism used by terrorists to change thoughts and behaviors, with the specific aim of increasing radicalization.

Despite a strong correlation effect, establishing a stronger cause and effect relationship through a better understanding of mechanisms at work is more difficult. In an attempt to explore these mechanisms, the focus was on exploring social media data. Using Foucault's analytic as a guide, investigation centered on exploring how forms of knowledge are transferred and propagated as well as what dimensions of the soul, terrorists are targeting (i.e. rational or affective). Media and in particular social media are an important tool for the propagation of the relationship between religion and terrorism [21]. Analysis of group pages revealed consistent discursive schemas. Some key schemas are summarized in Table 1 There were a number of common themes that emerged.

First, extremists do not view themselves as the aggressors, rather they merely respond to Western occupation and aggression. Second, terrorist figures are esteemed and regarded as hero's and/or martyrs. Third, the unity of Islam is a key discursive mechanism used to normalize the actions of extremists and prevent alienation from moderates. Further, it is used as a mechanism to try and swing moderates toward more extreme thinking. Fourth, restoring the glory of Islam is a key goal and is linked to the first point where it made clear that it is Islam (not terrorism) that is being attacked by the West and once again this seeks to unify Muslims. Finally, extremists are keen to contrast their different views on death to the West especially the concept of 'dunya' (Table 1). This list is by no means exhaustive but is does illustrate that common discursive schemas can be found across a wide variety of group pages.

In terms of targeting, the affective dimension is crucial for fuelling extremist views. As a case in point, the Voice of the Islamic Resistance 4 group page contains graphic images of dead Muslims designed to incite anger. Additionally, the choice of the word resistance is congruent with the first point in Table 1 of the discursive schema, Western oppression. Clearly, this discursive schema (Table 1) is designed to target the affective dimension highlighting that the West is against Islam. Another source of inspiration is interaction with western people 
Table 1 Discursive schemas on facebook

\begin{tabular}{|c|c|}
\hline Discursive element & Sample Posts $^{a}$ \\
\hline \multirow[t]{2}{*}{ Oppression/ Blaming of the West } & $\begin{array}{l}\text { [There's a 9/11 and 7/7 happening more than once a day in muslim }{ }^{b} \text { countries, afghanistan, pakistan, iraq, } \\
\text { palestine, chechneya, etc., etc.,] [UFWM0303] }\end{array}$ \\
\hline & $\begin{array}{l}\text { ["Because of my Islamic conscience I could not just sit back and watch the Jews while they were shooting } \\
\text { the Muslims like someone shooting birds." (12 year old boy)] }\end{array}$ \\
\hline \multirow{3}{*}{$\begin{array}{l}\text { [Some more moderate elements subscribe to } \\
\text { conspiracy theories] }\end{array}$} & Quoted by [HGB0621] \\
\hline & [what about the killing of palestinian,bosnian... is it justified ?] [AA0313] \\
\hline & $\begin{array}{l}\text { [OSAMA did not blow up the 2win towers them illuminati pple did it nd bush is } 1 \text { of them. 3.Osama isnt a } \\
\text { terrorist Americans, them Jew nd the british they kill thousands of our bros nd sis in iraq, gaza... 5. Osama } \\
\text { was a muslim my bro] [AA0309] }\end{array}$ \\
\hline $\begin{array}{l}\text { Defends actions of terrorists [Osama bin } \\
\text { Laden] }\end{array}$ & $\begin{array}{l}\text { [islam is sweet, and yes it is not osama obviously, for he too is a servant of Allah who can say on the day } \\
\text { of judgement h... ow he helped other muslims, how he had raised the banner of islam, with no shame, for } \\
\text { look at how many witnesses he has for his actions] [UFWM 0307] }\end{array}$ \\
\hline Unity of Islam & $\begin{array}{l}\text { [However he [bin Laden] is a brother in islam, and as muslims we are one body! where pain may hit one } \\
\text { part, affects the rest. You cannot judge, especially as you do not even begin to even try to understand our } \\
\text { religion, why do you think islam is the worlds greatest and fastest growing religion in the world.] } \\
\text { [UFWM0308] }\end{array}$ \\
\hline Restoring the glory of Islam & [and upholding islam, returning it to its glory, inshallah only by the will of Allah] [UFWM0311] \\
\hline \multirow[t]{3}{*}{ Embracing of death } & [Earth is a prison for believers and a paradise for unbelievers] [DF0601] \\
\hline & [We're just a traveler in this dunya $a^{c}$ and this dunya is just a trial for us.] [GBAM0603] \\
\hline & $\begin{array}{l}\text { [O ALLAH GRANT ME MARTYRDOM IN YOUR PATH AND OCCUR MY DEATH IN THE CITY OF YOUR PROPHET.] } \\
\text { IHGB0608] }\end{array}$ \\
\hline
\end{tabular}

a. Sources: Facebook Group Pages linked to Sheikh Anwar Al Awlaki et. al.

b. Incorrect spellings and grammar of original posts have been left as is throughout the table.

c. Dunya is an Arabic word meaning 'temporal world'.

on Islamic extremist sites that tend to harden their views. Here, westerners are allowed to discuss issues and as the following subsection illustrates they are baited due to extremist support of Osama bin Laden and other terrorists. Furthermore, extremists make it a war against Islam and in a sense they win by stirring up the Americans to be disrespectful to Allah, further reinforcing their alienation (see last post on in the following subsection).

Sample posts showing interactions to harden views. Interactions show high levels of polarization.

- [You're a stupid, ignorant sand nigger. Your buddy osama is dead, your next towel-head.] [ER0328]

- [@ethan you r dead wrong OSAMA is not dead just giving ya self alittle hope hahahaha!!!] [FI0329]

- [he is though... so? denial?] [ER0329]

- [Stop abusing sheikh anwar and Osama is a HERO OUR HERO. Get it.] [FI0329]

- [You're hypocrites. You think Americans are tyrants, you beat your women, and blow yourselves up and think your going to paradise.] [ER0330]

- [Wow wat about u superpowers yet you cant stop storms from destroying you. Allah is punishing $u$ for your deeds you want 2 finish ISLAM No u cant just fooling yo self.] [FI0330]

- [yo fatimah if you're so tight with allah, once you blow yourself up along with innocent men, women and children in exchange for 72 dunegook virgins, tell him i say go fuck yourself] [CC0331]

FI : Islamic extremist, ER and CC: Americans

Source: Facebook Group Page linked to Sheikh Anwar Al Awlaki

\section{The online environment allows for a more distributed form of power}

The targeting of training camps and the shift towards online forms of recruitment and training has resulted in a corresponding shift in power structures. This represents a shift towards more distributed network structures and a more 'leaderless' jihad [9,22]. Arid Uka is just one such case of a loner terrorist [8]. Others such as Tsouli start as isolated individuals and then become part of a group [9]. Consequently, the following hypothesis is proposed.

- H3: Online power relations follow a more distributed network structure, rather than a top down hierarchical structure.

Data from terrorist cases support this network structure without necessarily having specific forms of leadership. Nonetheless, there are cases that show some aberrance to this trend, most notably, the Benbrika case [17]. Here, one individual was clearly identified as the 
leader and guiding influence of the group. Nonetheless, there were no formal wider connections to a specific Islamic terrorist group. This case demonstrates that in small group structures there can exist a more formal hierarchical power structure. Yet such a power structure does not hold up well beyond small groups. Despite this, such small seemingly disconnected groups are part of a larger power structure or mechanism that warrants investigation.

\section{Use of discourse to maintain power}

Evidence suggests that cohesion of world-wide Islamic terrorism is maintained through discursive schemas. While there are clearly divergences between groups, each with its own particular ideology and focus, there are important concepts or rationalities that unite them to form the framework of this global power structure. Table 1 illustrates some of these common discursive features that have been collected from extremist groups on Facebook. Researchers in the field of Islamic terrorism will look at this table and see that it contains nothing new. It simply recreates well known discursive fields. However, this in and of itself is significant. The very fact that researchers are able to easily and clearly recognize common discursive elements of Islamic terrorism lend support to a model that holds the discursive framework as integral to the power structure of Islamic terrorism.

Islamic propaganda and discursive formations are rampant on the internet; this is a well known fact. However, this in and of itself is insufficient as a power structure to create radicalization and terrorism. The internet is filled with a vast variety of discursive schemas with many of them regarded as nothing more than fiction. Essentially, discursive schemas must be supported with some sort of normalizing process. In other words, the discourse in question must be presented as 'normal' and correct and discourses that run counter to it as false and abnormal. So the question becomes, how does this normalizing process work? Social media analysis of groups provides the best insights here.

\section{Shifting the 'norm' to the radical extreme}

After an initial focus on radical Islamic groups, I decided to broaden my focus to also encompass more moderate groups. This decision led to some significant findings. Several moderate Islamic groups tended to have input from more radical members. Consider the following example in the following subsection that challenges the views of a moderate. It seems that more radical Islamic elements are searching out and trying to influence more moderate Muslims thus shifting the normality of Muslim discourse in the more extreme or radical dimension. Note how the third post in the following subsection seeks to shift the notion of 'balance'.
Sample posts showing the challenging of a moderate by an extremist. Demonstrates a clear delineation with Western media.

- [Osama was d reason y many muslims were called terrorist] [SS0303]

- [ $i$ think you have been brain washed by the media . Listen before you say something you should think, concerning osama you need 2 do more research as to why he did that] [FI0322]

- ["Every muslim considers himself as balanced BUT the balance is according to the Prophet sallallahu alayhi wa salaama, so if he has participated in jihad 27 times in his life and we have not done this action even once, how then can we say we are balanced and that we follow the way of the Prophet sallallahu alayhi wa salaamh" (Masood Al Benin).] [HGB0517]

Source: Facebook groups

a. A well-known Islamic prophet

Another important aspect of the normalizing process is not just the discursive schemas but also where they come from and who authors these discourses. As an offshoot of social media, the extreme 'Inspire' magazine features articles from prominent terrorist leaders including Usama bin Laden. Quotes from prominent prophets, sheiks and terrorists are also common in Facebook postings. Interestingly, these terrorist leaders share certain physical characteristics as a symbol of their authority. These include long beards and classic Islamic robes. Such characteristics run contrary to much of the modus operandi presented that recommends its terrorist operatives to 'blend in' to Western culture in all aspects especially appearance. This paradox illustrates the importance of symbolic authority in the discursive formations of jihad. Additionally, group posts as illustrated below demonstrate high levels of respect for sheiks and their discursive schemas.

Sample posts illustrating loyalty to radical sheiks. Defending of extremist leaders is clearly evident here:

- [May Allah tala protect our sheikh and keep him away from all evil and harm, May he make his affairs easy for him ameen. When the disbeliever plot and plan Allah too plans and plots against them and Allah is the best of plotters and planners allahu akbar] [SB0332]

- [Mansha Allah, sheikh Anwar al Awlki may Allah reward him.] [AL0333]

- [salam, i just want us to know that victory is ours. i have heard sheikhs but nothing like you. Allahs promise is binding on Him and he will protect you both in duniya and akhira INSHA ALLAHU. salam and sakinah for you till we meet in Jannah either as 
a shaheed or whatever Allah decides for us] [AS0334]

Source: Facebook groups linked to Anwar Al Awlaki In spite of this symbolic authority, actual authority is does not belong to any particular individual or cleric. This is evident in social media groups that tend to focus on the discourse rather than on the authority of particular terrorists or sheiks.

\section{Discussion: developing an explanatory model of online radicalisation}

Having generated preliminary hypothesis and then further investigated aspects covering the normalization of radicalization and terrorism, it was confirmed that Foucault's analytic utilizing concepts of psychiatric power was an invaluable guiding framework for developing an explanatory model of online radicalization and terrorism. Consequently, this section will outline in detail this newly applied model in addition to some of its original theoretical foundations.

Power is reconceptualized as a move away from the use of force and coercion to affect change and a move towards more carefully planned, subtle, methodical, tactical routines [3]. To parallel radical Islamic extremism, it is a shift away from conversion by the sword, away from threats and forced action, and a move towards a disciplined, subtle and constant training; it is an immersion of the individual within this nebulous online context.

Although this online context has varying effects on different individuals with users having different motivations for online social interaction and engagement [23], forms of power are more subtle and widespread being a technique used to effect change. In other words, it is a method, a means to alter the attitudes and behaviors of users. Of course it is not always successful, but in the case of reproducing terrorism it does not have to be. Even changes in very small population sets can have devastating consequences. So the key question arises, how do forms of power work to promote radicalization and terrorism? This will be answered by looking at the key elements of psychiatric power as it relates to this topic.

\section{Self imposed isolation of individuals leads to radicalization}

To begin outlining this model, the internet or online environment will be contextualized an an institution. That said, the institutional does not necessarily need the traditional four walls, yet at the same time it does need to possess certain characteristics that define it.

\section{Social isolation}

First, an institution does need to possess a degree of social isolation [3]. This isolation is critical for normalizing behaviors and will be discussed in detail shortly. However, it is important to establish that this form of isolation is not a type of solitude, but rather insulation from pervasive outside influence, particularly alternative ideas and competing rationalities. In the case of radicalization, this seems to be a case of self imposed social isolation where individuals spend large amounts of time online engaging with radical materials.

\section{Disciplined regularity}

Second, an institution is a regulated and disciplined environment which stems historically from the ascetic exercises of the monastic tradition [3]. Research illustrates that terrorist's use of the internet parallels significant levels of regularity and discipline. This ranges from the use of the internet to coordinate and plan attacks as well as recruit and train individuals [10]. Most importantly, terrorist activity of the internet reflects elements of the master/servant type relationships of the monastic tradition as well as the expert/trainee relationships from the psycho-social sciences. A case in point are chat room forums where 'experts' train others in the specific tactical details of planning and conducting terrorist attacks including bomb creation skills, ambush skills and computer hacking [10].

\section{Access to normalizing discourses}

Thirdly, and perhaps most importantly is the use of the internet as an institution to normalize and reinforce behaviors. Research indicates that online users often actively seek out those who support their views and also interpret evidence in light of their belief and expectations [24]. Furthermore, this corroborating of opinion and beliefs often causes increases in opinion extremity [24]. This evidence, even if only true for a small subgroup of the population, demonstrates the actual and potential strength of the online institution in normalizing and strengthening attitudes and opinions. Other research has also shown that the internet does not increase participation in the political process [25], reinforcing its potential isolating affects. Overall, it is this isolation that forms the foundation of the online context.

\section{Online environment as a castle}

Perhaps one of the most salient symbols of institutional isolation is that of the castle. Specifically, the isolation and disciplinary regulation of a castle, its activities, timetable and even its surroundings imprints itself on the brain.' [3, p. 2]. Parallel to a physical castle, the internet is like a self-imposed virtual castle, a self-imposed form of isolation and training where one enters the institution both willingly and with a habitual, some may even say obsessive regularity. These virtual castles are particularly 
appealing to the disaffected young who seek fantasy narratives more so than religious or theological rigor [9].

To some, the internet as a castle is counterintuitive to what it represents, namely, diversity of opinion. While exposure to multiple viewpoints is critical to promoting diversity, group polarization is a phenomenon both in real world and online contexts when group exposure to debates simply results in the reinforcing of current beliefs in addition to a shift towards a more extreme position [24]. Group polarization stems from homophily, where like-minded individuals seek each other out, resulting in a mutual reinforcing of beliefs and opinions [24]. This phenomenon is well suited to recruiting and radicalizing individuals on the path to jihad and terrorism.

Given this phenomenon of group polarization coupled with the diverse and cosmopolitan nature of the internet, we have an interesting paradox. A place with a multitude of opinions and viewpoints while no doubt for some leads to promoting tolerance and diversity, but for others merely presents a choice of a multitude of selfimposed castles or virtual institutions. These online institutions are ready and waiting to reinforce current beliefs and opinions and even take them to a more extreme place. So the question arises, how do the disaffected and marginalized find and enter these radical Islamic virtual castles?

Previously, it was common for jihadi forums to be closed and password protected, only allowing those screened and chosen to enter [10]. Metaphorically, this meant that the gates of the castle were closed. This choice was made to protect those working within the institution from outsiders, namely intelligence agencies. However, this also meant that not only were the gates closed to unwanted intruders, they were also closed to new and potential recruits which was a significant disadvantage.

\section{Access to online 'castles' of radicalization}

Given the increasing emphasis on the use of Western social media, there has been a corresponding shift in the need to open up the virtual institution [10]. Many terrorist organizations now have open Facebook groups, which makes it much easier for radicals to enter these virtual institutions without the previous restrictions [10]. In addition, many of these sites are becoming much more media savvy, targeting and appealing to marginalized and disaffected youth. Despite these benefits, there is also the increased risk that terrorist organizations face of being infiltrated by intelligence agencies, and even prominent jihadi figures have warned their members and recruits about these potential dangers [10]. Nevertheless, given the enormous membership of social media sites such as Facebook (more than 500 million active users) and Twitter (more than 40 million active users) these are an important tool for finding and recruiting subjects for the virtual castle. These facts, in conjunction with the shift toward loner jihad wannabes targeting heroic fantasies [9], make this risk a necessary one for terrorist organizations to take.

Marginalized and disaffected individuals join interest groups that allow terrorists to specifically target individuals in a manner similar to the way a marketing group would target consumers [10]. Many of these are young males and females who are socially isolated and hence are seeking an identity. The danger here is that these individuals are voluntarily entering a virtual castle with a high degree of disciplined regularity. This disciplined or obsessive regularity is better known as problematic internet usage (PIU).

There have been a number of studies conducted on PIU especially in relation to loneliness and isolation. In terms of predictors of PIU on a group of university students: loneliness, depression and computer self-efficacy were the main predictors with loneliness then depression being the most significant [26]. For a younger cohort of secondary students, a strong relationship was found between hours of internet engagement and levels of loneliness [27]. This relationship in itself is problematic; nonetheless, other research studies also suggest that a negative spiral can occur. Those who were lonely or had poor social skills could develop PIU and this in turn had negative impacts on lifestyle factors such as home, school, work and relationships leading in further social isolation and loneliness [28]. Another study also supported the link between high internet use and poor social ties [29]. Consequently, those most likely to enter the obsessive regularity of the virtual castle are also those most vulnerable with problematic psychological antecedents. Others have also found that PIU is associated with low psychological wellbeing [23].

To further elaborate on the vulnerability of the disaffected, online interaction becomes a form of compensation for an individual's poor social skills [28]. Furthermore, the freedom of online interaction without the need for non-verbal cues often compounds the problems of real world interactions reinforcing the attraction of internet usage [23]. Unfortunately such individuals, in addition to those who shown sympathy to terrorist causes, are particularly vulnerable for recruitment and training given that they actually prefer online interaction.

\section{The online environment is an important context to normalise radical thinking and behavior}

Once terrorists have targeted sympathizers, the vulnerable or disaffected, their next task is to achieve a transformation; to 'normalize' the way in which they should think and ultimately act. Discipline and regularity are essential 
elements in order to normalize aberrant behaviors [3]. Online users achieve this order and socialization through their own regular or compulsive internet use that has a narrow focus on a particular group of rationalities.

A key aspect of engagement is facilitating the individual to self-disclose; however this is a very natural process online, with the internet promoting higher levels of self disclosure [23]. Furthermore, online users are generally more uninhibited [23], making them increasingly subject to forms of power. Specifically, this allows individuals to better self monitor and regulate their own behaviors using self subjectification [4]. Here individuals can compare their own frameworks against those of the extremist or terrorist group.

\section{Group polarization}

Homophily and group polarization are important concepts where like-minded individuals seek each other out and further strengthen their mindsets and even take them to more extreme levels [24]. A key dynamic of group polarization is group identity where individuals categorize themselves and others as in-group or out-of-group [24]. Group identification is particularly salient in political and ideological contexts [24]. For terrorist or extremist groups, this group identity is particularly important where individuals continually compare themselves against group categorizations and norms. Furthermore, threats to group identity tend to strengthen the homogeneity of the group [24]. This is particularly the case with terrorist groups, many of which highlight threats to their identity such as war crimes and maltreatment, bombing of civilians, as well as cases of discrimination and prejudice. Equally dangerous to strengthening group identity is the publication of victories against terrorists who are subsequently turned into heroes and martyrs [9]. Therefore, a strong group identity is imperative within the virtual institution.

Social media forums are battlegrounds for the hearts and minds of the vulnerable and disaffected. In fact the key to the success of radicalization is the victory of one idea over another [3]. This is an important objective of online radicalization, to replace moderate ideas with extreme ideals. Sageman is adamant that this is a battle for the hearts and minds of young Muslims which regularly go online to share their dreams and grievances [9]. Moreover, this is where terrorists attempt to suppress the realities and horrors of war and replace them with fantasy and heroic narratives [9]. These narratives are designed to give purpose, fulfillment and glory, in addition to providing an avenue for their grievances. What is particularly critical about these narratives is the way they capture the affective dimension.

\section{Targeting the affective dimension}

Monitoring and dealing with feelings is just as important as analyzing thoughts with many psychotherapeutic approaches also targeting the affective dimension [4]. Critically, for terrorists, Sageman argues that the affective dimension is more important than the rational dimension in explaining behavior and further links actions to a type of moral outrage over perceived injustices [9]. What is more concerning is that the virtual castles found through online social media are important forums to discuss issues that involve emotional triggers [24]. This is particularly so around political or controversial issues. These provide an important opportunity for terrorist recruiters to play on the feelings of disaffected young Muslims, with the aim of engendering radical feelings of injustice and hatred. To achieve this goal, terrorist leaders and radical clerics have carefully devised schemas or frameworks which they exercise.

\section{Schemas of knowledge}

A key aspect of normalizing behavior is the development of a prescriptive schema where forms of knowledge are combined with training, surveillance, monitoring and testing to ensure their adaptation by those within the institution [3]. In the case of institutions, frameworks of knowledge and expectations are developed about how to behave. In addition, these schemas were not value free but leaders have a clear body of theoretical knowledge about normality and how abnormality needs to be addressed [4]. In the virtual institution, radical Islamic leaders use their extreme views as the prescriptive schema that impose order, training and discipline upon those within this social media institution. Perhaps one of the most famous terrorists to make use of this concept was Younis Tsouli, also known as Terrorist 007, who produced a multitude of YouTube propaganda videos [10]. These videos were specifically designed to impose forms of knowledge about the path of jihad.

An important element in making up schemas is the concept of dispersion. This concept recognizes that diverse ideas make up a body of knowledge. A case in point is the concept of jihad that has a variety of divergent interpretations. However, a schema can and is still created by recognizing that: different variations make up a single discursive object; statements that make up a discourse are organized by form and connection; discourse is determined by more permanent and coherent concepts; and statements are grouped and regrouped according to themes [7]. The key point here is that extremist schemas while diverse are marked by prominent themes and persistent concepts that are echoed by many leaders and groups.

\section{The distributed nature of power in the online environment helps the process of radicalization}

Power to radicalize, in addition to being founded on schemas of knowledge, is a very meticulous and 
calculated power; with the modern asylum being one of disciplined and sophisticated routines rather than brute force [3]. This is critical in online environments as maintaining extremist or terrorist recruits is a difficult process, it is often gradual and slow. Also, although key leaders may be influential, power is not possessed by any individual; it is a circular relation that flows through many networks and individuals that make up that network [3]. Essentially, it is perfectly suited to the online environment. Further, this dispersion of hierarchies allows for a more tactical functioning of power [3], and is well suited to terrorist causes.

\section{The illusion of servanthood}

To explore this tactical functioning further, it is necessary to explore the illusion of servant hood. Terrorists on many online forums appear as servants giving their fellow radicals any assistance with tactical tools or moral support they need in order to carry out the global jihad. Fundamentally, what often occurs is high ranking and experienced terrorists become the servant of the novice radical while simultaneously exercising a form of power over them through their disciplined training regimes and schemas of radicalized thinking. As a consequence, new radicals become embedded within a framework of power. It is the locating within this framework of power that is critical in order for such power to be effective at transforming behaviors [3].

\section{Slow, structured and disciplined form of power}

When locating an individual within a framework of power, it is imperative not to conceptualize this as a repressive or controlling form of power. Rather, psychiatric power is a structured and productive power aimed at normalizing thoughts and behaviors contained within an institutions schema of knowledge [4]. Clearly, repressive forms of power would be very ineffective given the structure and dynamics of the online environment. However, a productive power that works in a subtle, regular and disciplined fashion is well suited to a network environment. To become effective this productive power must be created by what Foucault terms an 'apparatus of power' [3, p. 13].

\section{The relationship between power and discourse}

The key question in devising a framework is '... to what extent can an apparatus of power produce statements, discourses and, consequently, all the forms of representation that may then derive from it?' [3, p 13]. Overall, it is discourse that is the true leader of the online jihad [9]. Such discourses have been created by an apparatus of power and now seek to encompass all who enter the virtual castle. This apparatus of power seeks to suppress alternative forms of discourse that can compete or undermine it [7]. In the case of jihad, notions such as peace, compromise and moderacy must all be suppressed and categorized as ills while notions such as victory, war, martyrdom and sacrifice must be embraced.

\section{Power does not belong to an individual}

A final point on the flow of power is the disindividualisation of power. This is where power is decentered and not focused on one individual [4]. Online jihads are inspired, taught and trained by a wide variety of radical clerics, terrorists and terrorist groups. Despite this disindividualisation of power coupled with the circular and network relations of power, still present are forms of power dissymmetry through recognized symbolic authority [3]. In the traditional asylum, doctors symbolized their authority through a variety of physical features such as long white coats, white hair, expressive voice and prominent features [3]. For the online jihad, clerics also maintain a form of authority through physical appearance such as long beards, wearing of robes and the strong aggressive tone of voice. These forms of authority are a critical part of the apparatus of power that create the dominant schemas of knowledge use to regulate thoughts and behavior.

\section{Conclusion}

Given the rise of the online jihad as the third wave of radicals [9], it is critical to gain an understanding of the mechanisms of this process of radicalization. Through a grounded theory analysis of both terrorist cases and social media sites promoting jihad, Foucault's analytic on psychiatric power provides a solid analytical model for this process. Additionally, aspects of this model are also supported by findings from other researchers. In particular, this model encompasses the discourses of power and their interrelationship with schemas of knowledge that are carefully combined to normalize behavior. It is this transformation of ideology and behavior that is critical for producing terrorist acts. Of most concern is the way that radical Islamic elements seek to influence and transform more moderate and disaffected individuals including those within more moderate group forums.

Given the difficulty of data collection and the 'gap' between online radicalization and post terrorism case data, any model developed should be viewed as a partial, yet significant step in understanding the mechanisms that result in an individual or group undertaking terrorist acts. This paper has given another perspective that can add to the growing body of research on perhaps the most important tool used by Islamic extremists: the internet and in particular social media. Clearly, more research is needed in this vital area with the need to further explore mechanisms of radicalization and de- 
radicalization in order to prevent the spread of Islamic extremism and terrorism.

\section{Competing interests}

The author declares that they have no competing interests.

\section{Authors' information}

Dr Robyn Torok is currently undertaking her second PhD in security science. Her main research focus is online terrorism and in particular the use of social media to propagate terrorism.

Received: 19 February 2012 Accepted: 25 January 2013

Published: 12 February 2013

\section{References}

1. K von-Knop, Countering web-based Islamist narratives: conceptualizing an information war and a counter-propaganda campaign, in Hypermedia seduction for terrorist recruiting, ed. by B Ganor, K von-Knop, CAM Duarte (IOS Press, Amsterdam, 2007), pp. 169-187

2. C Mbakwe, D Cunliffe, Hypermedia seduction: further exploration of the process of "seductive" online user interactions, in Hypermedia seduction for terrorist recruiting, ed. by B Ganor, K von-Knop, CAM Duarte (IOS Press, Amsterdam, 2007), pp. 207-230

3. M Foucault, Lectures at the College de France 1973-1974, in Miche Foucault: psychiatric power, ed. by J LaGrange (Palgrave MacMillan, New York, 2006). Davidson Al (Series Editor)]

4. M Roberts, The production of the psychiatric subject: power, knowledge and Michel Foucault. Nurs Philos 6, 33-42 (2005)

5. Q Wiktorowicz, A genealogy of radical Islam. Studies in Conflict \& Terrorism 28, 75-97 (2005)

6. M Foucault, Nietzsche, genealogy, history, in Language, counter-memory, practice: selected essays and interviews, ed. by DF Bouchard (Cornell University Press, Ithaca, 1977)

7. D White, Foucault at work: archaeology, genealogy, and the dispositions of power. Eur Leg 14, 317-324 (2009)

8. J Burke, Islamist terrorism: the rise of the loners. http://www.guardian.co.uk/ commentisfree/2011/mar/04/islamic-terrorism-frankfurt-shooting-arid-uka

9. M Sageman, The next generation of terror. Foreign Policy March/April, 36-42 (2008)

10. G Weimann, Terror on facebook, twitter, and youtube. Brown Journal of World Affairs 16, 45-54 (2010)

11. CD Sutton, M David, Social research: an introduction, 2nd edn. (Sage Publications, London, 2011)

12. BJ Grim, AH Harmon, JC Gromis, Focused group interviews as an innovative quanti-qualitative methodology (QQM): integrating quantitative elements into a qualitative methodology. The Qualitative Report 11, 516-537 (2006)

13. C Hine, Internet research as emergent practice, in Handbook of emergent methods, ed. by SN Hesse-Biber, P Leavy (Guilford Press, New York, 2008), pp. 525-542

14. T Leonard, A Yusufzai, Times square bomb: Faisal shahzad profile. http:// www.telegraph.co.uk/news/worldnews/northamerica/usa/7678771/TimesSquare-bomb-Faisal-Shahzad-profile.html

15. Profile: major nidal malik hasan. http://news.bbc.co.uk/2/hi/8345944.stm

16. T Johnson, Threat of homegrown Islamist terrorism. http://www.cfr.org/ terrorism/threat-homegrown-islamist-terrorism/p11509

17. Benbrika \& Ors V The Queen [2010] VSCA 281 (25 October 2010). http://www. austlii.edu.au/au/cases/vic/NSCA/2010/281.htm

18. G Weimann, Terror on the Internet: the new arena, the new challenges (United States Institute of Peace, Washington, 2006)

19. C Brooks, Portland's Bomb plot: Who is Mohamed mohamud?. http://www. time.com/time/nation/article/0,8599,2033372,00.html

20. BM Jenkins, The al Qaeda-inspired terrorist threat: an appreciation of the current situation. http://www.rand.org/content/dam/rand/pubs/testimonies/ 2010/RAND_CT353.pdf

21. T Stanley, B Karl, H Jurgen, Transcendental aporias of global civil society. Political Theology 9, 477-502 (2008)

22. M Sageman, Understanding terror networks (University of Pennsylvania Press, Pennsylvania, 2004)

23. S Kang, Disembodiment in online social interaction: impact of online chat on social support and psychosocial well-being. Cyberpsychol Behav 10, 475-477 (2007)
24. S Yardi, D Boyd, Dynamic debates: an analysis of group polarization over time on twitter. Bull Sci Technol Soc 30, 316-327 (2010)

25. W Zhang, TJ Johnson, T Seltzer, SL Bichard, The revolution will be networked. Soc Sci Comput Rev 28, 75-92 (2010)

26. AA Ceyhan, E Ceyhan, Loneliness, depression, and computer self-efficacy as predictors of problematic internet use. Cyberpsychol Behav 11, 699-701 (2008)

27. L Deniz, Excessive internet use and loneliness among secondary school students. J Instr Psychol 37, 20-23 (2010)

28. J Kim, R LaRose, W Peng, Loneliness as the cause and the effect of problematic internet use: the relationship between internet Use and psychological well-being. Cyberpsychol Behav 12, 451-455 (2009)

29. CE Sanders, TM Field, M Diego, M Kaplan, The relationship of internet use to depression and social isolation among adolescents. Adolescence $35,237(2000)$

doi:10.1186/2190-8532-2-6

Cite this article as: Torok: Developing an explanatory model for the process of online radicalisation and terrorism. Security Informatics 2013 2:6.

\section{Submit your manuscript to a SpringerOpen ${ }^{\circ}$ journal and benefit from:}

- Convenient online submission

- Rigorous peer review

- Immediate publication on acceptance

- Open access: articles freely available online

- High visibility within the field

- Retaining the copyright to your article

Submit your next manuscript at $>$ springeropen.com 